\title{
Papers
}

\section{Does access to cardiac investigation and treatment contribute to social and ethnic differences in coronary heart disease? Whitehall II prospective cohort study}

\author{
Annie Britton, Martin Shipley, Michael Marmot, Harry Hemingway
}

\begin{abstract}
Objective To determine whether access to cardiac procedures and drugs contributes to social and ethnic differences in coronary heart disease in a population setting.

Design Prospective study with follow up over 15 years. Civil service employment grade was used as a measure of individual socioeconomic position. Need for cardiac care was determined by the presence of angina, myocardial infarction, and coronary risk factors.

Setting 20 civil service departments originally located in London.

Participants 10308 civil servants (3414 women; 560 South Asian) aged 35-55 years at baseline in 1985-8.

Main outcome measures Use of exercise electrocardiography, coronary angiography, and coronary revascularisation procedures and secondary prevention drugs.

Results Inverse social gradients existed in incident coronary morbidity and mortality. South Asian participants also had higher rates than white participants. After adjustment for clinical need, social position showed no association with the use of cardiac procedures or secondary prevention drugs. For example, men in the low versus high employment grade had an age adjusted odds ratio for angiography of 1.87 (95\% confidence interval 1.32 to 2.64$)$, which decreased to 1.27 (0.83 to 1.94) on adjustment for clinical need. South Asians tended to be more likely to have cardiac procedures and to be taking more secondary prevention drugs than white participants, even after adjustment for clinical need.

Conclusion This population based study, which shows the widely observed social and ethnic patterning of coronary heart disease, found no evidence that low social position or South Asian ethnicity was associated with lower use of cardiac procedures or drugs, independently of clinical need. Differences in medical care are unlikely to contribute to social or ethnic differences in coronary heart disease in this cohort.
\end{abstract}

\section{Introduction}

Low social position and South Asian ethnicity are both associated with increased risk of dying from coronary heart disease, ${ }^{12}$ but the impact of differential access to medical care on these inequalities remains uncertain. If access to coronary management matched coronary incidence, then low social position and South Asian ethnicity would be associated with higher rates of use. For social position, most studies, ${ }^{3-10}$ but not all, ${ }^{11-13}$ find the opposite-high social deprivation is associated with lower rates of coronary angiography and revascularisation. Several studies, mainly small and retrospective, report less aggressive treatment of South Asian people with coronary disease compared with white patients. ${ }^{14-22}$ Such potential healthcare disparities have stimulated calls in the United States and United Kingdom for remedial action..$^{23}$

Three interrelated questions remain unanswered. Firstly, in a general population that exhibits social and ethnic differences in rates of coronary heart disease, do differences exist in access to care? Population studies are lacking; all but a few studies are confined to patients who have sought hospital care for coronary disease and therefore exclude many people with angina in the community. ${ }^{12}$ Furthermore, studies have concentrated on invasive procedures, ignoring non-invasive investigation and secondary prevention, which may be particularly relevant in primary care. Secondly, how does the social deprivation of an individual patient, as opposed to an area, influence access to cardiac investigation and treatment? Most previous studies have used neighbourhood measures of social deprivation. ${ }^{3-11}$ One of the few prospective studies reporting individual social class, albeit confined to white men, found no effect on access to coronary angiography but lower revascularisation rates among men from non-manual occupations..$^{25}$ Thirdly, among South Asians, is the apparent lower use of cardiac investigation and treatment independent of or explained by their social position $?^{26}$ Previous studies have made little attempt to answer this question.

The Whitehall II prospective cohort study of civil servants offers the opportunity to consider each of these questions. Our objective was to determine whether access to cardiac procedures (exercise electrocardiography, coronary angiography, and coronary revascularisation) and secondary prevention drugs contributes to social and ethnic differences in coronary heart disease in a population setting.

\section{Methods}

All non-industrial civil servants aged $35-55$ years working in the London offices of 20 departments were invited to participate in the Whitehall II study. Recruitment took place during 1985-8, and the final cohort consisted of 10308 participants (3414 women). Between 1985 and 1999 self completed questionnaires were obtained at five phases of data collection and physical examination was conducted at three phases. Full details are published elsewhere. ${ }^{27}$ 


\section{Socioeconomic position}

We used civil service employment grade as a measure of socioeconomic position. On the basis of salary and work role, the civil service defines a hierarchy of employment grades, which we analysed in three levels: unified grades 1-7 (high), executive officers (medium), and clerical and support staff (low), as described previously. ${ }^{28}$

\section{Ethnicity}

We defined ethnicity according to the Office for National Statistics 1991 census categories. Of participants with known ethnicity, $9162(89.7 \%)$ described themselves as white; 560 participants were grouped as South Asian, of whom 74\% were Indian, 13\% Sri Lankan, 10\% Pakistani, and 3\% Bangladeshi.

\section{Clinical need}

We obtained evidence of incident angina and non-fatal myocardial infarction from questionnaire items at each follow up phase (symptoms of chest pain, recall of diagnosis by doctor), resting electrocardiograms (done at screening phases 1, 3 (1991-3), and 5 (1997-9) and classified according to the Minnesota code), and clinical records. Full details of ascertainment and classification are published elsewhere. ${ }^{29}$

A total of $10300(99.9 \%)$ participants were flagged at the NHS Central Registry. The registry notified us of the date and cause of death up to the end of 2001.

\section{Risk factors}

At baseline, standardised assessments were made of smoking, blood pressure, total cholesterol, body mass index, self reported diagnosis of diabetes, and family history of onset of coronary heart disease before age 55 years. In addition, the presence of the metabolic syndrome was assessed at phases 3 and 5 on the basis of oral glucose tolerance tests, plasma triglycerides and high density lipoprotein, waist:hip ratio, and systolic blood pressure. ${ }^{30}$

\section{Outcomes}

Exercise electrocardiography, angiography, and revascularisation A total of 7830 participants completed a phase 5 questionnaire ( $76 \%$ response rate from phase 1). Of these, 994 participants reported that they had had an exercise electrocardiogram, 403 reported having a coronary angiogram, and 124 reported having had coronary angioplasty or a coronary artery bypass graft operation (revascularisation procedure).

To investigate the possibility that employment grade or ethnicity may influence the reporting of medical care, we examined hospital discharge data from the NHS-wide clearing service. All 10308 participants were flagged with their NHS number for coronary angiography (code K634, K635, K636), coronary bypass grafting (K401-89) and angioplasty procedures (K491501) until the end of 2001. As the results obtained by using discharge data did not differ by grade or ethnicity from those obtained by using self reported data, we combined both sources. The final numbers used in the analysis were 525 angiograms (122 identified from discharge data alone) and 179 revascularisations (55 identified from discharge data alone).

\section{Secondary prevention drugs}

At the phase 5 follow up participants reported their use of prescribed drugs over the previous 14 days. We coded all drugs according to the British National Formulary and defined secondary prevention drugs as aspirin, $\beta$ blockers, lipid lowering agents, or angiotensin converting enzyme inhibitors.

\section{Statistical analysis}

We based the analyses of use of exercise electrocardiography on those participants who answered the question in the phase 5 questionnaire $(\mathrm{n}=7805)$. We based the analyses of coronary angiography and revascularisation on all 10308 participants and adjusted all these analyses for data source. We calculated the age adjusted rates of event outcomes and prevalence of having had a procedure (exercise electrocardiography, angiography, or revascularisation) by using direct standardisation. We used Cox's proportional hazards model to calculate adjusted rates and 95\% confidence intervals for event outcomes. We used logistic regression to calculate odds ratios of having had a procedure for each employment grade, with high grades as the reference group. We made statistical adjustments for age, evidence of coronary heart disease, diabetes, risk factors at baseline, and ethnicity. We similarly calculated odds ratios of having a procedure by ethnicity, with "white" as the reference group, adjusting in addition for employment grade. For the angiography and revascularisation analyses, we included an indicator of phase 5 attendance in order to minimise the potential bias from loss to follow up. To assess the quality of medical care we calculated the age adjusted prevalence of use of secondary prevention drugs among participants who attended phase 5 and had a history of myocardial infarction or angina.

\section{Results}

Table 1 shows that incident coronary morbidity and mortality were higher among lower employment grades than among higher grades and higher among South Asians than among white participants. For example, in men, the age adjusted rate ratio for incident angina and myocardial infarction was 1.66 (95\% confidence interval 1.32 to 2.10 ) for low versus high employment grades and 1.95 (1.28 to 2.96) for South Asians compared with white participants. Risk factors tended to be adverse in low employment grades and among South Asians. South Asians were less likely to be in a high employment grade than were white participants.

\section{Social position}

Men and women in the low employment grades reported higher use of exercise electrocardiography (age adjusted proportion $17.5 \%$ in men and $10.6 \%$ in women) than did those in the high employment grades ( $14.7 \%$ in men and $8.6 \%$ in women) (table 2). When we adjusted for history of coronary heart disease during follow up and baseline risk factors, we found no evidence of an overall grade gradient in either men or women. Men and women in the low employment grades had the highest use of angiography with adjustment for age alone, but no grade differences existed when we added clinical need and other risk factors to the models. Similarly, participants in the low grades had the highest use of revascularisation when we adjusted for age alone, but among men these differences were removed by further adjustment. Employment grade was not associated with taking secondary prevention drugs among the subgroup of participants with a history of angina or myocardial infarction (table 3 ).

\section{Ethnicity}

South Asian men and women were more likely to have an exercise electrocardiogram or coronary angiography than white participants, even after adjustment for clinical need and employment grade (table 4). We found less evidence for ethnic differences in revascularisation procedures. Further adjustment for presence of the metabolic syndrome or diabetes or abnormality on resting electrocardiogram did not attenuate any 
Table 1 Age adjusted prevalence and mean coronary risk factors at baseline by employment grade and ethnicity and rates of subsequent coronary events

\begin{tabular}{|c|c|c|c|c|c|c|c|}
\hline & \multicolumn{4}{|c|}{ Civil service employment grade } & \multicolumn{3}{|c|}{ Ethnicity } \\
\hline & High & Medium & Low & $P$ value for trend & White & South Asian & $P$ value \\
\hline \multicolumn{8}{|c|}{ Baseline $(n=10$ 308) } \\
\hline \multicolumn{8}{|l|}{ Number: } \\
\hline Men & 2647 & 3607 & 641 & - & 6394 & 348 & - \\
\hline Women & 381 & 1336 & 1696 & - & 2868 & 212 & - \\
\hline \multicolumn{8}{|c|}{ Mean age (years): } \\
\hline Men & 45.2 & 43.1 & 44.6 & $<0.001$ & 43.8 & 46.6 & $<0.001$ \\
\hline Women & 43.2 & 44.1 & 46.7 & $<0.001$ & 45.3 & 44.6 & 0.012 \\
\hline \multicolumn{8}{|c|}{ South Asian (\%): } \\
\hline Men & 0.8 & 6.5 & 18.6 & $<0.001$ & - & - & - \\
\hline Women & 1.3 & 3.3 & 11.1 & $<0.001$ & - & - & - \\
\hline \multicolumn{8}{|c|}{ High employment grade (\%): } \\
\hline Men & - & - & - & - & 42.0 & 6.1 & $<0.001$ \\
\hline Women & - & - & - & - & 13.3 & 2.5 & $<0.001$ \\
\hline \multicolumn{8}{|c|}{ Current smoking (\%): } \\
\hline Men & 9.7 & 17.4 & 34.0 & $<0.001$ & 15.0 & 26.4 & $<0.001$ \\
\hline Women & 13.8 & 20.3 & 27.8 & $<0.001$ & 25.4 & 4.6 & $<0.001$ \\
\hline \multicolumn{8}{|c|}{ Systolic blood pressure $(\mathrm{mm} \mathrm{Hg}):$} \\
\hline Men & 124.4 & 124.7 & 125.4 & 0.07 & 124.7 & 122.4 & 0.03 \\
\hline Women & 119.5 & 119.6 & 119.5 & 0.89 & 119.4 & 118.9 & 0.75 \\
\hline \multicolumn{8}{|c|}{ Total cholesterol $(\mathrm{mmol} / \mathrm{l})$ : } \\
\hline Men & 6.0 & 6.0 & 6.0 & 0.91 & 6.0 & 6.2 & 0.13 \\
\hline Women & 5.8 & 5.9 & 5.9 & 0.72 & 5.9 & 5.7 & 0.006 \\
\hline \multicolumn{8}{|c|}{ Body mass index $\left(\mathrm{kg} / \mathrm{m}^{2}\right)$ : } \\
\hline Men & 24.4 & 24.6 & 25.1 & $<0.001$ & 24.6 & 24.2 & 0.002 \\
\hline Women & 23.7 & 24.3 & 25.3 & $<0.001$ & 24.4 & 24.9 & 0.005 \\
\hline \multicolumn{8}{|c|}{ Diabetes mellitus (\%): } \\
\hline Men & 0.5 & 1.1 & 1.7 & 0.002 & 0.7 & 3.4 & $<0.001$ \\
\hline Women & 0.7 & 0.6 & 1.5 & 0.04 & 0.7 & 4.1 & $<0.001$ \\
\hline \multicolumn{8}{|c|}{ Family history of early heart disease (\%): } \\
\hline Men & 6.6 & 7.0 & 5.7 & 0.85 & 6.7 & 10.0 & 0.06 \\
\hline Women & 6.6 & 9.9 & 7.6 & 0.68 & 8.5 & 13.5 & 0.10 \\
\hline \multicolumn{8}{|c|}{ Follow up (rates per 1000 person years) } \\
\hline \multicolumn{8}{|c|}{ Incident myocardial infarction and angina: } \\
\hline Men & 8.8 & 10.8 & 14.9 & $<0.001$ & 7.9 & 13.9 & $<0.001$ \\
\hline Women & 9.5 & 11.8 & 13.4 & 0.05 & 9.3 & 20.1 & $<0.001$ \\
\hline \multicolumn{8}{|c|}{ Fatal coronary heart disease or non-fatal myocardial infarction: } \\
\hline Men & 2.7 & 3.5 & 5.7 & $<0.001$ & 2.9 & 5.7 & 0.002 \\
\hline Women & 1.4 & 1.5 & 1.7 & 0.62 & 1.5 & 3.3 & 0.008 \\
\hline \multicolumn{8}{|c|}{ All cause mortality: } \\
\hline Men & 2.6 & 3.1 & 5.8 & $<0.001$ & 2.7 & 3.7 & 0.009 \\
\hline Women & 1.3 & 2.8 & 3.2 & 0.04 & 2.7 & 0.4 & 0.005 \\
\hline
\end{tabular}

For the continuous measures systolic blood pressure, total cholesterol, and body mass index, the standard deviations in the whole study population were 14.1, 1.2, and 3.1 in men and 15.7, 1.2 , and 4.3 in women.

of these effects (data not shown). South Asians also tended to be more likely to take secondary prevention drugs than white participants-for example, among men with a history of angina or myocardial infarction, 34\% of South Asians were taking $\beta$ blockers compared with $14 \%$ of white men (see table on bmj.com).

\section{Sex}

Women were less likely to have coronary investigations and treatments than men within each grade (table 2) and ethnic group. When adjusted for age, coronary heart disease, employment grade, and ethnicity, the odds ratios of women having an exercise electrocardiogram, angiogram, and revascularisation compared with men were 0.51 (95\% confidence intervals 0.42 to 0.62$), 0.48$ (0.38 to 0.62 ), and 0.25 (0.15 to 0.40 ).

\section{Discussion}

\section{Social position}

In this population based cohort, which exhibits the ubiquitous inverse social gradient in coronary morbidity and mortality, we found no evidence of a social gradient in use of cardiac procedures and drugs after adjustment for clinical need. This suggests that use of medical care broadly reflects clinical need and does not explain the well documented social gradient in coronary morbidity and mortality. Differential access to medical care has previously been proposed as an explanation for the relation between social position and health event ${ }^{31}$; we found no evidence to support this.

\section{Ethnicity}

South Asian civil servants, predominantly Indian, had a twofold increased risk of coronary morbidity and mortality compared with white civil servants. Contrary to the hypothesis that South Asians might be disadvantaged in their access to cardiac care, we 
Table 2 Use of exercise electrocardiography, coronary angiography, and coronary revascularisation by employment grade

\begin{tabular}{|c|c|c|c|c|c|c|}
\hline \multirow[b]{2}{*}{ Procedure } & \multicolumn{3}{|c|}{ Employment grade (men) } & \multicolumn{3}{|c|}{ Employment grade (women) } \\
\hline & High & Medium & Low & High & Medium & Low \\
\hline \multicolumn{7}{|l|}{ Exercise electrocardiography } \\
\hline No of participants & 2785 & 2329 & 316 & 444 & 1071 & 860 \\
\hline $\begin{array}{l}\text { No of exercise } \\
\text { electrocardiograms }\end{array}$ & 410 & 301 & 56 & 34 & 95 & 98 \\
\hline Age adjusted percentage & 14.7 & 13.5 & 17.5 & 8.6 & 8.9 & 10.6 \\
\hline \multicolumn{7}{|l|}{ Odds ratio $(95 \% \mathrm{Cl})$ adjusted for: } \\
\hline Age & 1 & 0.89 (0.76 to 1.05) & $1.23(0.90$ to 1.67$)$ & 1 & 1.07 (0.71 to 1.62$)$ & 1.28 (0.84 to 1.96$)$ \\
\hline Age + CHD & 1 & $0.76(0.63$ to 0.90$)$ & $1.06(0.75$ to 1.50$)$ & 1 & 0.95 (0.62 to 1.46$)$ & $1.12(0.72$ to 1.74$)$ \\
\hline Age $+\mathrm{CHD}+$ risk factors ${ }^{*}$ & 1 & $0.76(0.62$ to 0.93$)$ & $0.93(0.60$ to 1.43$)$ & 1 & 0.83 (0.51 to 1.38$)$ & 0.81 (0.47 to 1.39$)$ \\
\hline \multicolumn{7}{|l|}{ Coronary angiography† } \\
\hline No of participants & 2647 & 3607 & 641 & 381 & 1336 & 1696 \\
\hline No of angiograms & 148 & 191 & 49 & 10 & 34 & 93 \\
\hline Age adjusted percentage & 5.0 & 5.7 & 8.8 & 2.7 & 2.6 & 5.6 \\
\hline \multicolumn{7}{|l|}{ Odds ratio $(95 \% \mathrm{Cl})$ adjusted for: } \\
\hline Age & 1 & 1.16 (0.93 to 1.45) & 1.87 (1.32 to 2.64$)$ & 1 & 0.95 (0.46 to 1.96$)$ & 2.04 (1.04 to 4.01$)$ \\
\hline $\mathrm{Age}+\mathrm{CHD}$ & 1 & 1.01 (0.79 to 1.29) & 1.52 (1.04 to 2.23$)$ & 1 & 0.85 (0.41 to 1.79$)$ & 1.73 (0.86 to 3.45$)$ \\
\hline $\mathrm{Age}+\mathrm{CHD}+$ risk factors ${ }^{*}$ & 1 & 0.92 (0.71 to 1.19$)$ & 1.27 (0.83 to 1.94$)$ & 1 & 0.75 (0.35 to 1.64$)$ & 1.25 (0.60 to 2.61$)$ \\
\hline \multicolumn{7}{|l|}{ Coronary revascularisation† } \\
\hline No of participants & 2647 & 3607 & 641 & 381 & 1336 & 1696 \\
\hline No of revascularisations & 53 & 85 & 14 & 1 & 4 & 22 \\
\hline Age adjusted percentage & 1.8 & 2.6 & 2.7 & 0.3 & 0.3 & 1.2 \\
\hline \multicolumn{7}{|c|}{ Odds ratio $(95 \% \mathrm{Cl})$ adjusted for: } \\
\hline Age & 1 & 1.50 (1.06 to 2.14$)$ & 1.41 (0.77 to 2.58$)$ & & $1 \ddagger$ & 3.62 (1.35 to 9.71$)$ \\
\hline $\mathrm{Age}+\mathrm{CHD}$ & 1 & 1.31 (0.90 to 1.90$)$ & 1.02 (0.54 to 1.92$)$ & & 1 & 3.26 (1.21 to 8.78$)$ \\
\hline $\mathrm{Age}+\mathrm{CHD}+$ risk factors $^{*}$ & 1 & 1.24 (0.83 to 1.85$)$ & $1.14(0.57$ to 2.30$)$ & & 1 & 2.62 (0.94 to 7.33$)$ \\
\hline
\end{tabular}

$\mathrm{CHD}=$ coronary heart disease.

Some analyses are based on smaller numbers (owing to missing variables). The social gradient was similar in this restricted group to that in the full cohort.

*Smoking, systolic and diastolic blood pressure, total cholesterol, body mass index, diabetes, ethnicity, and family history.

†Based on whole cohort and adjusted for baseline risk factors and phase 5 response indicator.

łHigh and medium grade combined owing to small numbers.

found some evidence of higher rates of use of procedures in South Asians than in white participants, even after adjustment for coronary morbidity, risk factors, and the metabolic syndrome. This may be interpreted as South Asian patients and their doctors responding to the widely perceived increased risk of heart disease with lower thresholds for action. Indeed, a survey on attitudes to health seeking behaviour found that South Asians were more likely to seek immediate care for (hypothetical) anginal symptoms than white people. ${ }^{32}$ In the appropriateness of coronary revascularisation study, South Asians had more consultations with a general practitioner in the year before angiography than did white patients. ${ }^{22}$

In socioeconomic terms, the South Asians working in the civil service represent a relatively advantaged and homogeneous group. This offers the opportunity to separate the potential confounding link between social position and ethnicity, ${ }^{26}$ thus strengthening our finding that, in this study, ethnic differences in care do not explain ethnic differences in coronary heart disease.

\section{Limitations of the study}

Clearly, civil servants do not represent the extremes of social position, nor the diversity of South Asian communities. However, the Whitehall II study shows marked social and ethnic differences in coronary heart disease, similar in magnitude to those reported in many other general population studies, which warrant exploration for the determinants. Although largely based in the southeast of England, by 1995, owing to progressive relocation of civil service departments, $44 \%$ of participants lived outside Greater London. Furthermore, many Whitehall participants live in areas that are among the most socially deprived in the country. On the basis of the Townsend deprivation index (based on unemployment, overcrowding, non-car ownership, and non-home ownership) approximately $20 \%$ of men and $40 \%$ of women participants live in the most deprived fifth of electoral wards in England.

The clinical "careers" of people with angina or myocardial infarction evolve over time, punctuated by changes in morbidity and in healthcare response. The Whitehall II study, in common with other population based studies, is not able to characterise the detailed history of appropriateness of each management step in this career, nor were we able to explore waiting times.

Table 3 Age adjusted use of secondary prevention drugs by employment grade among participants with a history of angina or myocardial infarction. Values are percentages unless stated otherwise

\begin{tabular}{|c|c|c|c|c|c|c|c|c|}
\hline & \multicolumn{4}{|c|}{ Employment grade (men) } & \multicolumn{4}{|c|}{ Employment grade (women) } \\
\hline & High $(\mathrm{n}=332)$ & $\begin{array}{c}\text { Medium } \\
(\mathrm{n}=345)\end{array}$ & Low $(n=54)$ & $P$ value for trend & High ( $n=51)$ & $\begin{array}{c}\text { Medium } \\
(\mathrm{n}=184)\end{array}$ & Low $(n=171)$ & $P$ value for trend \\
\hline Aspirin & 24 & 26 & 31 & 0.33 & 8 & 10 & 12 & 0.31 \\
\hline$\beta$ blockers & 14 & 16 & 18 & 0.22 & 9 & 11 & 9 & 0.86 \\
\hline Lipid lowering agents & 14 & 14 & 19 & 0.41 & 7 & 6 & 5 & 0.40 \\
\hline $\begin{array}{l}\text { Angiotensin converting enzyme } \\
\text { inhibitors }\end{array}$ & 10 & 10 & 10 & 0.91 & 11 & 8 & 11 & 0.77 \\
\hline
\end{tabular}


Table 4 Use of exercise electrocardiography, coronary angiography, and revascularisation by ethnicity

\begin{tabular}{|c|c|c|c|c|}
\hline & \multicolumn{2}{|c|}{ Men } & \multicolumn{2}{|c|}{ Women } \\
\hline & White & South Asian & White & South Asian \\
\hline \multicolumn{5}{|l|}{ Exercise electrocardiography } \\
\hline No of participants & 5065 & 222 & 2045 & 134 \\
\hline No of exercise electrocardiograms & 670 & 66 & 162 & 30 \\
\hline Age adjusted percentage & 13.5 & 26.6 & 7.7 & 20.6 \\
\hline \multicolumn{5}{|l|}{ Odds ratio $(95 \% \mathrm{Cl})$ adjusted for: } \\
\hline Age & 1 & 2.43 (1.79 to 3.29$)$ & 1 & 3.51 (2.26 to 5.45$)$ \\
\hline $\mathrm{Age}+\mathrm{CHD}$ & 1 & 2.04 (1.44 to 2.89) & 1 & 2.63 (1.63 to 4.22$)$ \\
\hline $\mathrm{Age}+\mathrm{CHD}+$ risk factors $^{*}$ & 1 & 1.98 (1.30 to 3.01$)$ & 1 & 2.32 (1.27 to 4.27$)$ \\
\hline \multicolumn{5}{|l|}{ Angiography† } \\
\hline No of participants & 6294 & 348 & 2868 & 212 \\
\hline No of angiograms & 327 & 46 & 98 & 21 \\
\hline Age adjusted percentage & 5.1 & 12.7 & 3.3 & 10.4 \\
\hline \multicolumn{5}{|l|}{ Odds ratio $(95 \% \mathrm{Cl})$ adjusted for: } \\
\hline Age & 1 & 2.78 (1.97 to 3.90$)$ & 1 & $4.04(2.42$ to 6.76$)$ \\
\hline Age $+\mathrm{CHD}$ & 1 & 2.15 (1.46 to 3.17$)$ & 1 & 2.90 (1.68 to 5.01$)$ \\
\hline Age + CHD + risk factors ${ }^{*}$ & 1 & 2.13 (1.39 to 3.27$)$ & 1 & 3.94 (2.05 to 7.57$)$ \\
\hline \multicolumn{5}{|l|}{ Revascularisation $\dagger$} \\
\hline No of participants & 6294 & 348 & 2868 & 212 \\
\hline No of revascularisations & 130 & 17 & 20 & 2 \\
\hline Age adjusted percentage & 2.1 & 4.6 & 0.6 & 0.8 \\
\hline \multicolumn{5}{|l|}{ Odds ratio $(95 \% \mathrm{Cl})$ adjusted for: } \\
\hline Age & 1 & 2.25 (1.33 to 3.82$)$ & 1 & $1.79(0.41$ to 7.83$)$ \\
\hline $\mathrm{Age}+\mathrm{CHD}$ & 1 & 1.45 (0.83 to 2.56$)$ & 1 & $1.16(0.26$ to 5.17$)$ \\
\hline $\mathrm{Age}+\mathrm{CHD}+$ risk factors $^{*}$ & 1 & 1.45 (0.76 to 2.75$)$ & 1 & $2.34(0.43$ to 12.7$)$ \\
\hline
\end{tabular}

$\mathrm{CHD}=$ coronary heart disease

Some analyses are based on smaller numbers (owing to missing values). The age adjusted effect of ethnicity in these restricted groups was similar to that in the full cohort.

*Smoking, systolic and diastolic blood pressure, total cholesterol, body mass index, diabetes, employment grade, and family history.

†Adjusted for baseline risk factors and phase 5 response indicator.

\section{Strengths of the study}

Civil service employment grade has proved an informative tool with which to investigate the influence of social position on health. Access to use of a car is a measure of social position available in wider settings and also may influence travel to healthcare facilities. We further tested our associations with car access and found higher rates of coronary heart disease and greater use of procedures in those participants without access to a car (data not shown). This mirrors our findings with employment grade.

The Whitehall II study offers, as far as we are aware, unique data with which to explore the impact of access to cardiac care. We carried out detailed, repeated assessments of clinical need extending beyond symptoms and resting electrocardiograms to include the metabolic syndrome. The metabolic syndrome is associated with low social position and South Asian ethnicity and may influence decisions about testing and treatment. Furthermore, whereas other studies have examined hospital admissions for revascularisation, the Whitehall II study is alone in reporting the more prevalent, earlier stages of non-invasive and invasive investigation.

\section{Quality of care and secondary prevention}

Our demonstration that the quantity of medical care in terms of procedure rates is not lower by social position or South Asian ethnicity does not exclude the possibility that the quality of care differs. $^{33}{ }^{34}$ Procedures might be less appropriate, ${ }^{35}$ and the outcomes may be worse, among people of low social position or South Asian ethnicity. One of the few studies to test this hypothesis directly found no evidence that this was the case when examining ethnic differences in revascularisation..$^{22}$ In Whitehall II, use of secondary prevention, a direct marker of the quality of care, showed no differences by social position and tended to be higher among South Asians. Since these data were collected, government policy has emphasised the equitable increase in sec- ondary prevention on the basis of disease registers in primary care.

Sex

The findings on social position and ethnicity were consistent in men and women; however, women had substantially lower rates of use of cardiac procedures and secondary prevention than men, consistent with other studies. ${ }^{36}{ }^{37}$ Reasons for this may include less severe disease among women, less willingness to undergo procedures, differences in language used to describe symptoms, ${ }^{38}$ or bias by physicians.

\section{Implications for research and policy}

If medical care is not important in explaining social and ethnic differences in coronary disease, this strengthens the case for investigating other behavioural, biological, and psychosocial factors. Healthcare systems should monitor social and ethnic differences in treatment rates and prognosis; explaining differences in incidence of disease demands population based cohort studies in which people are recruited regardless of contact with medical care.

\section{Conclusion}

In this population based study we found no evidence that low social position or South Asian ethnicity was associated with lower use of cardiological investigation or treatment independent of clinical need. Differences in access to medical care are unlikely to explain the social and ethnic differences in coronary heart disease.

Professor Peter W Macfarlane of the Royal Infirmary, Glasgow, reviewed all the electrocardiographs. We thank all participating civil service departments and their welfare, personnel, and establishment officers; the Occupational Health and Safety Agency; the Council of Civil Service Unions; all participating civil servants in the Whitehall II study; and all members of the Whitehall II study team. 


\section{What is already known on this topic}

Low social position and South Asian ethnicity are associated with higher risk of developing coronary heart disease

Previous studies which suggested social and ethnic differences in access to care were limited by ecological measures of social position, poor ability to distinguish ethnic from social effects, and lack of population base

\section{What this study adds}

Social position was not associated with use of cardiac procedures or secondary prevention, once account was taken of clinical need

South Asians tended to be more likely to undergo cardiac procedures and be on secondary prevention drugs than were white participants

Access to medical care is unlikely to explain the social or ethnic differences in coronary morbidity

Contributors: $\mathrm{AB}$ and $\mathrm{HH}$ had the idea for the study. $\mathrm{AB}$ wrote the first draft and incorporated comments from all co-authors. MS did all statistical analyses. $\mathrm{AB}$ is the guarantor.

Funding: The Whitehall II study has been supported by grants from the Medical Research Council; British Heart Foundation; Health and Safety Executive; Department of Health; National Heart Lung and Blood Institute (HL36310), US, NIH; National Institute on Aging (AG13196), US, NIH; Agency for Health Care Policy Research (HS06516); and the John D and Catherine T MacArthur Foundation Research Networks on Successful Midlife Development and Socioeconomic Status and Health. AB and MS are supported by the British Heart Foundation. HH is supported by a public health career scientist award from the Department of Health. MM is supported by an MRC research professorship.

Competing interests: None declared.

Ethical approval: Each phase of the Whitehall II study has received ethical approval from the research ethics committee of UCL Hospitals.

1 Shaw M, Dorling D, Gordon D, Davey Smith G. The widening gap: health inequalities and policy in Britain. Bristol: Policy Press, 1999.

2 Wild S, McKeigue P. Cross sectional analysis of mortality by country of birth in England and Wales, 1970-92. BMJ 1997;314:705-10.

3 Gittelsohn AM, Halpern J, Sanchez RL. Income, race, and surgery in Maryland. Am J Public Health 1991;81:1435-41.

4 Payne N, Saul C. Variations in use of cardiology services in a health authority: comparison of coronary artery revascularisation rates with prevalence of angina and coronary mortality $B M J 1997 \cdot 314 \cdot 257-61$.

5 Alter DA, Naylor D, Austin P, Tu JV. Effects of socioeconomic status on access to invasive cardiac procedures and on mortality after acute myocardial infarction. $N$ Engl J Med 1999;341:1359-67.

6 MacLeod MCM, Finlayson AR, Findlay IN. Geographic, demographic, and socioeconomic variations in the investigation and management of coronary heart disease in Scotland. Heart 1999;81:252-6.

7 Anderson GM, Grumbach K, Luft HS, Roos LL, Mustard CM, Brook R. Use of coronary artery bypass surgery in the United States and Canada: influence of age and income. JAMA 1993;269:1661-6.

8 Manson-Siddle CJ, Robinson MB. Superprofile analysis of socio-economic variations in coronary investigation and revascularisation rates. J Epidemiol Community Health in coronary inves.

9 Ben-Shlomo Y, Chaturvedi N. Assessing equity in access to health care provision in the UK: does where you live affect your chances of getting a coronary artery bypass graft? J Epidemiol Community Health 1995;49:200-4.

10 Coory M, Scott IA, Baade P. Differential effect of socioeconomic status on rates of invasive coronary procedures across the public and private sectors in Queensland, Australia. J Epidemiol Community Health 2002;56:233-4.
11 Kee F, Gaffney B, Currie S, O'Reilly D. Access to coronary catheterisation: fair shares for all? BMJ 1993;307:1305-7.

12 Morris RW, McCallum AK, Walker M, Whincup PH, Ebrahim S, Shaper AG. Cigarette smoking in British men and selection for coronary artery bypass surgery. Hear 1996;75:557-62.

13 Jones M, Ramsey J, Feder G, Crook AG, Hemingway H. Influence of practices' ethnicity or deprivation on access to angiography: an ecological study. Br J General Practice 2004;54:423-8.

14 Lowry, PJ, Glover DR, Mace PJ, Littler WA. Coronary artery disease in Asians in Birmingham. Br Heart J 1984;52:610-3.

15 Shaukat N, de Bono DP, Cruickshank JK. Clinical features, risk factors, and referral delay in British patients of Indian and European origin with angina matched for age delay in British patients of Indian and European origin
and extent of coronary atheroma. BMJ 1993;307:717-8.

16 Dhawan JBC. Angiographic comparison of coronary artery disease between Asians and Caucasians. Postgrad Med 1994;70:625-30.

17 Lear JT, Lawrence IG, Burden AC, Pohl JEF. A comparison of stress test referral rates and outcomes between Asians and Europeans. J R Soc Med 1994;87:661-2.

18 Lear JT, Lawrence IG, Pohl JE, Burden AC. Myocardial infarction and thrombolysis: a comparison of the Indian and European populations on a coronary care unit. $J R$ Coll Physicians Lond 1994;28:143-7.

19 Mukhtar HLW, Littler WA. Survival after myocardial infarction in Asian and white patients in Birmingham. Br Heart J 1995;73:122-4.

20 Wilkinson P, Sayer J, Laji K, Grundy C, Marchant B, Kopelman P, et al. Comparison of case fatality in south Asian and white patients after acute myocardial infarction: obsercase fatality in south Asian and white pari
vational study. BMJ 1996;312:1330-3.

21 Goldsmith I, Lip GY, Tsang G, Patel RL. Comparison of primary coronary artery bypass surgery in a British Indo-Asian and white Caucasian population. Eur Heart J 1999;20:1094-100.

22 Feder G, Crook AM, Magee P, Banerjee S, Timmis AD, Hemingway H. Ethnic differences in invasive management of coronary disease: prospective cohort study of patients undergoing angiography. BMJ 2002;324:511-6.

23 National Institutes of Health. Strategic research plan to reduce and ultimately eliminate health disparities. Bethesda, MD: National Institutes of Health, 2000. (Available at www.nih.gov/about/hd/strategicplan.pdf)

24 Acheson D. Inequalities in health: report of an independent inquiry. London: Stationery Office, 1998.

25 Morris RW, Whincup PH, Papacosta O, Walker M, Thompson A. Inequalities in coronary revascularisation during the $1990 \mathrm{~s}-$-evidence from the British regional heart study. Heart (in press).

26 Nazroo JY. South Asian people and heart disease: an assessment of the importance of socioeconomic position. Ethn Dis 2001;11:401-1

27 Marmot MG, Smith GD, Stansfeld S, Patel C, North F, Head J, et al. Health inequalities among British civil servants: the Whitehall II study. Lancet 1991;337:1387-93.

28 Marmot M, Shipley M, Brunner E, Hemingway H. Relative contribution of early life and adult socioeconomic factors to adult morbidity in the WII study. J Epidemiol Community Health 2001;55:301-7.

29 Hemingway H, Shipley M, Britton A, Page M, Macfarlane P, Marmot M. Prognosis of angina with and without a diagnosis: 11 year follow up in the Whitehall II prospective cohort study. BMJ 2003; 327: 895-900.

30 Brunner EJ, Hemingway H, Walker BR, Page M, Clarke P, Juneja M, et al. Adrenocorti$\mathrm{cal}$, autonomic and inflammatory causes of the metabolic syndrome: nested cal, autonomic and inflammatory causes of
case-control study. Circulation 2002;106:2659-65.

31 Adams P, Hurd MD, McFadden D, Merrill A, Ribeiro T. Healthy, wealthy, and wise? Tests for direct causal paths between health and socioeconomic status. $J$ Econometric 2003;112:3-56.

32 Chaturvedi N, Rai H, Ben-Shlomo Y. Lay diagnosis and health-care seeking behaviour for chest pain in south Asians and Europeans. Lancet 1997;350:1578-83.

33 Friscella K, Franks P, Gold MR, Clancy CM. Inequality in quality: addressing socioeconomic, racial, and ethnic disparities in health care. JAMA 2000;283:2579-84.

34 Goldman DP, Smith JP. Can patient self-management help explain the SES health gradient? Proc Natl Acad Sci USA 2002;99:10929-34.

35 Hemingway H, Crook AM, Feder G, Banerjee S, Dawson JR, Magee P, et al. Underuse of coronary revascularization procedures in patients considered appropriate of coronary revascularization procedures in patients con
candidates for revascularization. N Engl J Med. 2001;344:645-54.

36 Raine R. Does gender bias exist in the use of specialist health care? J Health Serv Res Policy 2000;5:237-49.

37 Hippisley-Cox J, Pringle M, Crown N, Meal A, Wynn A. Sex inequalities in ischaemic heart disease in general practice: cross sectional survey. BMJ 2001;322:832.

38 Philpott S, Boynton P, Feder G, Hemingway H. Gender differences in descriptions of angina symptoms and health problems immediately prior to angiography: the ACRF study. Soc Sci Med 2001;52:1565-75.

(Accepted 25 May 2004)

doi $10.1136 /$ bmj.38156.690150.AE

International Centre for Health and Society, Department of Epidemiology and Public Health, University College London Medical School, London WC1E 6BT Annie Britton lecturer in epidemiology

Martin Shipley senior lecturer in medical statistics

Michael Marmot professor of epidemiology and public health

Harry Hemingway reader in clinical epidemiology

Correspondence to: H Hemingway h.hemingway@ucl.ac.uk 